\title{
Passeig literari a Borriana
}

\author{
Pau Piqueras i Blasco (paupiquerasiblasco@gmail.com) \\ Institut Torras i Bages de l'Hospitalet de Llobregat
}

\author{
Sempre et mirava, Borriana, com \\ fores, un temps, d'il-luminat gravat, \\ carregant tones al vaixell, al port, \\ de mandarina.
}

(Estellés, 2018: 297)

\section{Introducció}

La importància històrica de Borriana és indiscutible: el nom del poble, d'etimologia àrab, ja apareix al Llibre dels fets de Jaume I. Segles més tard, durant el xIX, esdevé el màxim exportador de taronges, i d'aquesta capitalitat econòmica se'n deriva la rellevància cultural: d'ací els edificis d'estil modernista que trobem en alguns carrers del centre $\mathrm{o}, \mathrm{i}$ aquest és el tema que ens ocuparà en aquest article, la seua aparició en diversos textos literaris. A partir d'aquests escrits, propose un recorregut pel poble on les lletres s’impregnen del paisatge urbà.

\section{Al poble}

Iniciem el recorregut al carrer de Sant Ernest, on vivia quan era xicoteta la poeta borrianenca Carme Rufino. Al poema VIII, «A l'asfalt blanc del carrer de Sant Ernest», del llibre Psalms d'Heber, conta records d'infantesa:

\section{$[\ldots]$}

Ara, mentre escric, penso que res no canvia, ni el temps, que continuo dibuixant somnis en un paviment de paper.

A fora de la meva cambra, la llum a poc a poc enfosqueix les

[finestres

d'un altre carrer que també és meu

i jo, amb un altre clarió a la mà, somio mantenir blanca la vorera, ratllat asfalt

en un temps que en el record encara no es mou. (Rufino, 2003: 27)

Aprofitant que som prop del Camí d'Onda, podem contemplar l'edifici roig que va inspirar Joan Pla per a Don Fabrizzio i un cadàver al Prince Building (2011). La novella té com a eix principal l'aparició d'un cadàver al pàrquing d'un edifici senyorial: aquest 
fet alça un gran aldarull a la comarca, perquè el cos correspon al d'un regidor i diputat provincial amb competències en obres públiques. L'entrellat argumental de la novellla té tristes similituds amb la política valenciana, fins al punt que el lector es pot acabar preguntant si el que narra podria tenir algun vincle amb la realitat.

Anem en direcció al centre del poble, agafant el carrer de Sant Pasqual i trencant després pel carrer de Sant Xutxim: aquests dos carrers ressegueixen el traçat de l'antiga muralla àrab, de la qual no es conserven vestigis coneguts. Però l'interès d'aquest recorregut va més enllà d'açò: les façanes de banda i banda tenen un regust de l'opulència de cent anys

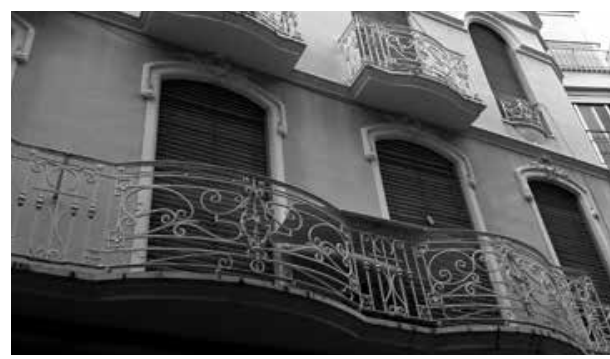

Casa premodernista del carrer Sant Xotxim. (Foto: P. Piqueras). ençà. L'estil arquitectònic ve d'un temps d'esplendor econòmica, quan Borriana era el major exportador de taronges a l'exterior, principalment al nord d'Europa. Estem parlant de les darreres dècades del segle XIX $\mathrm{i}$ les primeres del $\mathrm{xx}$, quan es popularitza entre els exportadors de primera classe ferse construir cases d'un estil premodernista eclecticista. Això, faig un incís, també ho trobem al Barranquet, que conserva el traçat arrodonit de la muralla.

Josep Palomero, a Pell de taronja, repassa totes les cases que es construeixen entre els anys 1890 i 1940 que resten als nostres carrers com una reminiscència miraculosament conservada de les glòries del passat:

A l'inici de la dècada dels anys seixanta, coincidint amb l'expansió econòmica general, amb l'especulació del sòl i amb la propagació de l'ascensor, la Pell de taronja començà a marcir-se, a arrugar-se i a assecar-se, i a Borriana es començaren a assolar exemplars notoris de cases, i d'altres de no tan cèlebres, alçats amb orgull feia escassos lustres. Sembla com si, durant aquells anys, hom hagués volgut diluir qualsevol vestigi de memòria històrica; ben probablement, així hagués succeït, si Borriana hagués conegut una altra font de recursos, més enllà de l'explotació comercial del taronger. No fou així, per dissort o per ventura, i aquell procés de destrucció tingué unes proporcions concretes, encara que en la major part dels casos, també ben salvatges. D'una manera o d'una altra, Pell de taronja revela, com si fos visible d'un iceberg, la voluntat dels borrianencs d'aquell mig segle d'estar a l'altura de les seues circumstàncies. Els contemporanis, potser hauríem de prendre'n nota. (Palomero, 1986: 16)

D'aquesta decadència en l'exportació de la taronja en parla també Joan Pla, a la seua novella El secret del collar de diamants. I, si ens dirigim cap a la plaça Major, hi podem veure la casa de Bernat, el protagonista, al bell mig del poble:

El pare de Bernat era fill d'antics exportadors de taronja, però ell va plegar el negoci quan va ensumar que l'exportació del daurat fruit tenia els dies comptats. Ell, amb bon ull, va desviar els estalvis cap a la promoció immobiliària. Vivien en un pis gran al centre del poble. Des del pis, Bernat podia contemplar la plaça Major, on hi havia l'ajuntament, i el gran campanar 
octogonal, de pedra tallada, que s'elevava imponent per damunt de tots els edificis del voltant. (Pla, 2010: 15)

Antoni Alcover també parla de la plaça Major quan, mentre estudia les diferents varietats dialectals del català, fa una estada a Borriana després de recórrer els carrers d'Onda i de Vila-real, la qual descriu negativament com un «fanguer de llot de les basses ferestes [...]» amb els carrers fets amb «broixa de camp» (Alcover, 2010: 188), que en comparació amb els carrers borrianencs descrits com «drets y plans; les cases moltes renovades», contrasta pel nivell de vida entre poblacions veïnes. Descriu, a més a més de l'església del Salvador, el poble i la gent que hi habita. En transcric un fragment respectant les grafies prefabrianes:

Just vaig arribar a l'església parroquial, qui es moderna, ample y baixeta. Les voltes son de mitx punt amb llunets. L'ábside, per lo que vaig poder veure de defora, era ogival; però en passál barroquisme, y feu maig. Ara estuquen tot l'interior y posen vergarons y birimboyes xurrigueresques per les arestes y panys de les voltes, pilastres, arcades y gornisaments. Per assí encara, desgraciadament, la reacció arqueológica, artística, del bon gust, no es arribada. Lo notabilíssim es el retaule de l'altar major, de gust plateresch ben pur. Ve a esser un triptich, de tres compartiments verticals y quatre horitzontals, enquadrats per unes feixes delicioses. Les verticals son parells de columnetes molt ayroses, sobreposades, que tenen al mitx dos nitxets, un demunt l'altre, amb figures de sants ben garrides; les faixes horizontals son els gornisaments d'aquelles columnetes, poch sortits, amb fullatjes en el fris, de casi gens de relleu. (Alcover, 2010: 188)

D’ací anem cap al Pla, on s'esdevé un dels passatges més importants de la novel·la $E l$ jardín de las Hespérides, de Vicente Abad:

De repente, una mujer gritó «ßBarcos, pan y trabajo!» y al instante la multitud comenzó a repetir aquellas tres palabras que, como un conjuro, galvanizaron todas las energías uniéndolas para derribar los muros que sujetaban la rabia tanto tiempo contenida. (Abad, 2005: 14)

I és també al Pla on, si fem un salt temporal i parlem d'història, Jaume I planta el campament per fer el setge a Borriana, emprant tècniques d'enginyeria preindustrials com el «castell de fust». La revista Buris-ana, en un article de Josep Lluís Gil, descriu amb claredat com el rei va construir, assessorat pel seu enginyer, un fonèvol, una mena de torre d'assalt per a atacar la muralla. Cite el fragment de la Crònica o Llibre dels Feits:

Lo castell de fust haurà dos vases de cada una part, e seran quatre, menys de dos altres que n'haurà en la frontera de cada una part, denant e detràs, e aquells fermaran les vases, e fer-los ha dos solers, la un en la mijania del castell, e l'altre sus alt: e en l'alt seran ballesters la meitat e hòmens que apedregaran a aquells sarraïns qui pujaran al mur, e puis los crestians pujaran per aquella torre derrocada, e ells no ho poran defendre, per les ballestes e per les pedres que seran en lo castell, e el castell serà en l'extrem del vall, e així porà's pendre la vila. (Jaume i, 1982: 180-181)

Aquest «castell de fust» s'havia de situar al sud del Pla, aproximadament on comença el carrer del Barranquet. I de fet, des d'aquí també es pot veure l'església major i el campanar, 
que es troben a la zona per on el castell es va malmetre després d'haver-lo abandonat perquè no estava preparat per a protegir els soldats dels atacs amb sagetes que els sarraïns els llançaven des de dalt del mur (Gil, 2008: 11).

Ja que estem situats al sud del Pla, aprofitem per enfilar cap al carrer d'Ausiàs March, on es troba el col·legi de la Consolació. Ací hi ha un mapa fet amb fang i amb relleu de la península Ibèrica, impressionant si es té en compte que el van elaborar alumnes dels anys 50. Joan Garí l'evoca al llibre On dormen les estrelles:

I ha arribat el dia, finalment, en què la vella geografia oculta de Nuestras Vidas ha eixit una altra vegada a la llum. Acabat de pintar, protegit per una pantalla transparent de metacrilat, m'he sorprés d'entrada en no reconéixer el mateix objecte que jo vaig ajudar a modelar. Els anys juguen aquestes males passades, però aquestes muntanyes i aquests rius per on torna a circular l'aigua -no s'hi ha estalviat cap detall- són els mateixos que els de fa seixanta anys, això és evident.

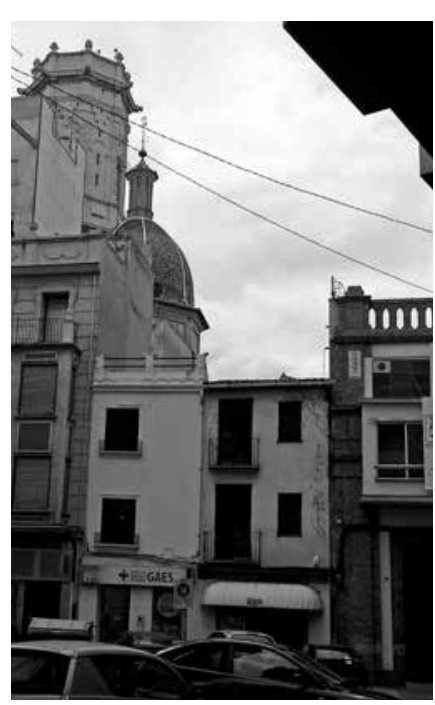

Ubicació aproximada del «castell de fust».(Foto: P. Piqueras). (Garí, 2004: 192)

Tot el procés de l'argila fou viscut amb una especial gaubança pels més menuts de la milícia cartogràfica: hi van xipollejar a pler, amb conats de batalles llancívoles que, per sort, van ser tallades en sec. Miraculosament, la faena avançà a bon ritme i la península va anar prenent forma com una estranya nau avarada enmig del pati. (Garí, 2004: 194)

Seguint el nostre camí, ara fem rumb cap a la Mercè, un dels centres culturals més importants del poble: ací és on es fan classes d'art, exposicions i on hi ha també la Biblioteca Municipal. La lectura que ens acompanya en aquesta ocasió és el llibre de Vicent Franch, Palamarinar, on l'autor ens conta un viatge cap al seu interior, una catarsi a través dels seus alter ego: l'escriptor pacient, el nacionalista esperançat, el ciutadà compromès, l'erudit de les coses de la terra, el conversador apassionat i irònic, el professor universitari, el lector intel-ligent, l'amic amatent, el malalt d'amor pel seu país, i alguns altres. Podríem descriure l'obra de Franch com un monòleg interior de caràcter autobiogràfic o memorialístic. És la seua veu la que ens parla de la infantesa, dels amics, de la geografia íntima, del compromís polític i cívic amb el país, de les lectures, dels noms de les coses que ens envolten, de les seues obsessions, etc. El llenguatge és deliciosament enrevessat.

Recupere el fragment de la descripció de la Mercè, on Franch ens la descriu a partir de la seva evolució:

El mateix em va ocórrer amb una porta sempre tancada a l'antic Convent de la Mercè, desamortitzat el 1837, i des d'aleshores ençà les seues activitats civils. Aquell antic convent, ara Casa de la Cultura, després d'haver-se sotmès a una reconstrucció que només ha aprofitat els espais definits i els murs exteriors i interiors de l'edifici, havia estat emprat pels menesters més diversos en èpoques 
successives: ara escoles municipals, adés Casa de la Vila, en uns temps presó i, recentment, seu de les organitzacions del glorioso movimiento nacional. (Franch, 1994: 106-107)

No gaire lluny de la Mercè hi ha la casa de Maria, el personatge protagonista femení d'una altra novel·la de Joan Pla, El secret del collar de diamants, també marcada històricament per l'exportació de la taronja:

Els pares de Maria, el senyor Tomàs i la senyora Maria, vivien en una casa tradicional situada al barri popular de la Mercè. La casa havia pertangut a l'avi matern, el senyor Balaguer, antic comerciant de taronja. Els pares de Maria, tot i la construcció de grans i còmodes pisos al centre de la ciutat o a l'eixampla, s'havien negat a abandonar la casa pairal i bescanviar-la per un luxós pis en l'eixampla de les noves, assolellades i amples avingudes, com havia fet la major part de la classe burgesa. Es trobaven a gust en aquest barri de gent sobretot gran i modesta. (Pla, 2010: 9)

\section{Al terme}

Ara que ja hem visitat uns quants racons literaris del poble, podem fer via cap als afores. Anem cap al terme de Borriana, en direcció cap a Almassora i agafem la CV-18 cap a Nules. El primer lloc que visitarem és l'alqueria del Batle, un casalici del segle XVII ubicat al costat del cementeri, a la dreta de la carretera que, de fet, es va desviar a posta per no enderrocar la casa. Apareix al llibre de Glòria Olivares, Tractes amb el diable:

Els fars d'algun que altre cotxe que passava per la carretera em permeteren distingir alguns detalls de l'edifici. Constava de planta baixa i dos altures. Unes enormes portes de ferro rovellat constituïen l'entrada principal, rematada per dos guardacantons calcaris cònics i un brancal de pedra. Els carreus de la base de la façana encaixaven a la perfecció. De la cantonada esquerra, la més pròxima a l'autovia, eixia un permòdol senzill. Les finestres que flanquejaven la porta formaven dos rectangles enreixats simètrics. Dalt de les planxes de metall oxidat hi havia un balcó que havien transformat en una finestra amb un ampit de fusta. Més amunt, unes finestres rectangulars contigüies a la volada de la teulada indicaven que allà era la pallissa. El parament de la dreta, cap a la banda del cementeri, es perllongava amb el mur d'un pati al qual s'accedia gràcies a una porta de barrots. Només la façana estava pintada amb calç blanca. La resta de l'alqueria tenia el color roig dels bolos barrejats amb fang. (Olivares, 2003: 27-28)

Continuem pel terme de Borriana, per aquests camins i carreteres envoltats de tarongers. Ara anem de camí a l'alqueria de Mascarós, que també descriu Vicente Abad a El jardín de las Hespérides:

Marsenta había nacido con el siglo en la alquería de Mascarós, un inhóspito caserón próximo al Camí de Carnissers, enclavada en medio de la propiedad de la que su

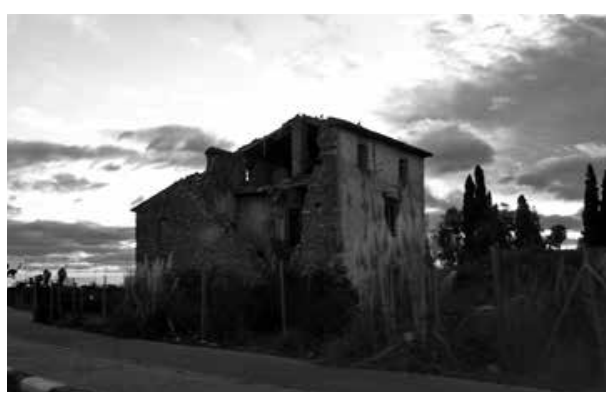

Casa del Batle. (Foto: P. Piqueras). 
padre, al igual que había sido su abuelo, era medianero. Y esto era motivo de orgullo familiar porque, como le había contado su progenitor una cálida noche de verano sentados bajo la enorme higuera que crecía delante de la casa, su abuelo y el señor Mascarós fueron los primeros que plantaron un huerto de naranjos en el término municipal. (Abad, 2005: 7-8)

Després de la visita a Casa Mascarós, ens n’anirem prop de les alqueries de Santa Bàrbara, on es troba el castell de canyes que menciona Joan Garí a On dormen les estrelles. Aquest castell no és pròpiament una construcció arquitectònica, sinó un espai natural a la desembocadura del riu Millars, on hi ha molt de canyís. Ací és on s'oculta el protagonista de la història en temps de repressió, quan afusellen altres habitants de la contornada:

El nostre Castell de Canyes estava en un indret privilegiat, des del qual podríem haver assistit, amb obstinació i perspicàcia, a tot aquest festival macabre, però aquesta perspectiva, ara, m'ha resultat horrible. [...]

La primera vegada que vaig veure un home mort a trets em va sorprendre la força terrible amb què el seu cos s'arrapava a terra, com si, en haver-se-li extirpat la vida violentament, s'haguera exacerbat en ell el principi de la gravetat. (Garí, 2004: 111)

Una vegada eixim del Millars, a mà esquerra ens trobem amb La Cotorra, una alqueria que va pertànyer a José Iturbi. La descriu Jean Dalrymple, una dona americana que va fer-li de secretària, a September Child, el seu llibre de memòries. I és així com un poble xicotet com Borriana apareix a una obra nord-americana:

"La Cotorra", as Iturbi's finca or huerto is called, seemed at the end of nowhere ans still does. It is a huge orange ans tangerine grove on the Mediterranean Sea near the little town of Burriana, half-away between Valencia and Castellon-de-la-Plana, several miles off the Valencia-Barcelona main road, and I have often wondered how he ever found it. (Dalrymple, 1963: 172-173)

\section{A la platja i al port}

Amb això hem finalitzat l'etapa del terme i ens podem dirigir cap al Grau. Arribar-hi és senzill: solament hem de passar entre les alqueries de Santa Bàrbara, sempre prioritzant els caminets que es dirigeixen a la mar, com el camí d'Etxebarria. I recuperem dos textos més de la poeta borrianenca Carme Rufino: «VI. Una flaire de salnitre i aigua» $\mathrm{i}$ «IX. Les pedres de la platja del grau no tenen rostre»., també del poemari Psalms d'Heber. En cite alguns fragments:

\footnotetext{
VI. Una flaire de salnitre i aigua

[...]

Mentre ressegueixo els límits de la vorera, m'absorbeix la sina tot el deler viu de l'aigua

i sé que la mar em venç en eròtica brisa

esquitxant-me els ulls amb blaus desigs d'abraçada.
} 
L'aigua viva m'atrau i esdevé bull l'esquena, adés més templada.

La calor fixa els marges dels pensaments;

en una ment opalina i ara ardent, desperta l'ànima fresca, blanca onades de llimes, torbada plenamar d'escumes.

Ací, en passar junt a l'espigó nou que trena al Grau una cabellera cana, he vist més joves les pedres de la vora, més clares les arrugues de sorra, vestigis d'una besada ben llarga. (Rufino, 2003: 23)

IX. Les pedres de la platja del grau no tenen rostre

$[\ldots]$

Ensopidament cegues s'amunteguen en el tacte, cruixen ensalivades amb l'obstinada violència, indolents a l'amorosa embranzida de l'aigua càlida, rendides a l'esgarrapada cruel de la nit freda.

[...]

No,

les pedres del Grau no tenen rostre.

Blanques com els segons d'un oblit secularment constant, balbes d'un temps absolut i inexistent, sense rostre també, ni miren ni senten des de l'enorme llosa de marbre exànime que s'escampa sota el sol. (Rufino, 2003: 28-30)

Des del Grau continuem per l'avinguda de la Mediterrània fins a arribar a l'hotel Aloha: un enclavament important a la novel-la de Joan Pla L'illa del faraó, perquè és on van quedar Eduard i l'egiptòleg d'Alacant per tal d'aclarir els misteris del fill del faraó de l'illa Groga: «-D'acord. L'esperarem a les dotze a la porta de l'hotel Aloha, que està situat al port. Supose que el seu cotxe té matrícula d'Alacant...». (Pla, 1997: 156)

Des de l'hotel ens dirigim cap al port

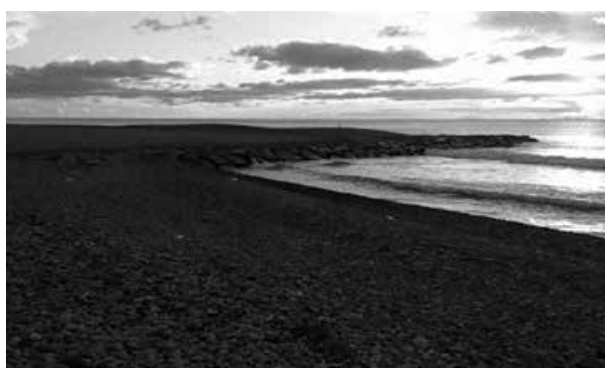

Platja del Grau de Borriana. (Foto: P. Piqueras). seguint recte i a la primera rodona girem a l'esquerra. Ací és on Eduard, Meritxell i els seus amics - també de L'illa del faraó- quedaven, es reunien per xerrar i fer altres activitats juvenils. El lloc exacte on quedaven era el Mur, que començava on és ara la rodona $\mathrm{i}$ 
arribava fins al final del port. Fa gairebé trenta anys que el van enderrocar, i ara solament ens el podem imaginar resseguint el traçat de la carretera.

He triat un parell de textos que evoquen el port: una anècdota ens la conta Glòria Olivares a Maig: 10 anys de contes. A «La jove i el mariner cubà» recorda el que li va succeir quan, fent de música, va anar amb l'Agrupació Filharmònica Borrianenca a tocar al port, molt a prop del Club Nàutic, el dia de la Mare de Déu del Carme:

«Un any més la mateixa processó», pensava. «Cada any és igual. Ma vida sempre serà igual», s'entristia. Lamentant la seua infelicitat, oí una veu al tòs:

- ¡Tocadnos algo!

En girar el cap trobà tres hòmens forasters, el més gran dels quals estava més a prop d'ella que els altres.

-Què! -exclamà la jove desconfiada perquè no havia entés les intencions de l'interlocutor.

-Que nos toquéis algo. Nosotros somos de Cuba y antes de partir en el barco queremos escuchar la música tan bonita de este maravilloso país.

Ara sí que l'havia entés. (Olivares, 2007: 128)

I, per a cloure la ruta, ja que estem situats molt prop del Club Nàutic, ens dirigirem cap a aquest local. És ací on, com recorden a L'illa del faraó, arriben tots els rumors sobre el que passa al port, atesa la conversa amb el director del museu arriba al pescador: «Imagine que deu buscar alguna cosa que no heu trobat al vaixell, perquè el senyor Ballester diu que et va dur a recuperar el rellotge que et va regalar ton pare - em va dir. Ho sap tot el Nàutic». (Pla, 1997: 135).

\section{Consideracions finals}

Comptat i debatut, en aquesta ruta literària podem satisfer el desig de recórrer el poble en unes tres o quatre hores en bicicleta, seguint els fets que hi apareixen a les obres que hem llegit. Us imagineu parlar amb un diable, descobrir el misteri d'una mena de «faraó valencià» $\mathrm{i}$ al mateix temps fer un tast poètic sobre uns dels majors paradisos que tenim com és la platja del Grau? Doncs bé, tot açò és possible a Borriana, una capital cultural que, si m'ho permet Franch, és la nostra palamarinar, un lloc «on dormen els secrets a què tenim dret. [...] És la paraula fresca en la llengua adient; i no és el condol dels inactius. [...] És lluny i és a prop. Hi és i se'l pot trobar» (Franch, 1994: 164). I seguint la ruta marcada és possible que interioritzem una part la història literària borrianenca.

\section{BIBLIOGRAFIA}

AваD, V. (2005): El jardín de las Hespérides, València, Editorial El Nadir.

Alcover, A.M. (2001): Dietaris de les eixides (1900-1902), vol. I, a cura de Maria Pilar Perea, Barcelona, Publicacions de l'Abadia de Montserrat.

Andrés Estellés, V. (2018): «Apartament de novembre», Obra completa, vol. v,València, Edicions Tres i Quatre.

Dalrymple, J. (1963): September Child the Story of Jean Dalrymple, Nova York, Editorial: Dodd, Mead \& Company. 
Franch i Ferrer, V. (1994): Palamarinar, Borriana, Agrupació Borrianenca de Cultura i Publicacions de la Universitat Jaume I.

GARí, J. (2004): On dormen les estrelles, Alzira, Edicions Bromera.

Gil i CABRERA, J.L. (2008): «"Lo castell de fust...”, enginyeria militar aplicada a la conquesta de Borriana per Jaume I», Buris-ana, 204, 8-13.

JAUME I (1982): Crònica o Llibre dels Feits, a cura de Ferran Soldevila, Barcelona, Edicions 62.

Olivares i MuÑoz, G. (2003): Tractes amb el diable, València, Tabarca Llibres.

Olivares I MuÑoz, G. (2007): «La jove i el mariner cubà», Maig: 10 anys de contes, Catarroja, Perifèric Edicions, 127-129.

Palomero, J. (1986): Pell de taronja, Borriana, Fundació Rafael Martí de Viciana.

Pla, J. (2011): Don Fabrizzio i un cadàver al Prince Building, la Pobla Llarga, Edicions 96.

PLA, J. (2010): El secret del collar de diamants, València, Tabarca Llibres.

PLA, J. (1997): L'illa del faraó, Alzira, Edicions Bromera.

Rufino, C. (2003): Psalms d'Heber, Barcelona, Viena Edicions.

\section{BIONOTA}

Pau Piqueras va nàixer a Borriana l'any 1989, i després de passar tota la joventut al poble va anar a estudiar a la Universitat de València la carrera de Filologia Catalana. Des de llavors, ha fet el màster per dedicar-se a la docència i el màster d'Estudis Avançats en Llengua i Literatura catalanes, especialitat en Lingüística. Més tard, va escriure de forma intermitent en diverses revistes, ha fet de corrector lingüístic i en l'actualitat, a banda de treballar com a professor, també estudia Criminologia a la UOC. 